\title{
Complications of inguinal hernia repair in children: A tertiary hospital experience
}

\author{
Chukwubuike KE iD
}

Kevin Emeka Chukwubuike, Department of Surgery, Enugu State University Teaching Hospital, Enugu, Nigeria.

\begin{abstract}
Background: Repair of inguinal hernia is one of the most frequently performed procedures in pediatric surgery. Objectives: The aim of this study was to evaluate the complications we encountered following repair of inguinal hernia in children.

Methodology: This was a retrospective study done in children aged 15 years and below who had complications following inguinal hernia repair (both emergency and elective) at the pediatric surgery unit of Enugu State University Teaching Hospital (ESUTH) Enugu, Nigeria, between January 2014 and December 2018.

Results: A total of 1243 cases of pediatric inguinal hernia repairs were performed during the study period. Out of this, 123 patients developed complications, accounting for $9.9 \%$ of the total cases. There was male predominance with a median age of 1 year. Most of the complications were noted in infants undergoing emergency repairs. Scrotal complications were the most common complications which resolved on non-operative treatment. Other complications in descending order of frequency included wound infection, hernia recurrence, testicular atrophy and sensory disturbances in the inguinal region. There was no mortality following the surgeries.

Conclusion: Pediatric inguinal hernia repair is a procedure with potential complications more so in infants following an emergency repair. Preoperative parental counseling and timely referral are mandatory.
\end{abstract}

Key words: Children; Complications; Inguinal hernia; Repair; Tertiary hospital.

\section{INTRODUCTION}

Tnguinal hernia is one of the most common conditions in children and is a frequent reason for surgical intervention'. Inguinal hernia has an incidence of 3.5 to $5.0 \%$ in full term infants while in preterm babies;

Access this article online

Website: www.jkmc.com.np

DOI: https://doi.org/10.3126/jkmc.v9i2.35527

\section{HOW TO CITE}

Chukwubuike K E.Complications of inguinal hernia repair in children: A tertiary hospital experience. J Kathmandu Med Coll. 2020;9(2):102-6.

Address for correspondence

Dr. Kevin Emeka Chukwubuike

Department of Surgery

Enugu State University Teaching Hospital

Enugu, Nigeria.

E-mail: chukwubuikeonline@yahoo.com

Copyright @ 2020 Journal of Kathmandu Medical College (JKMC)

ISSN: 2019-1785 (Print), 2091-1793 (Online)

(i) (S) This work is licensed under a Creative Commons Attribution-Non Commercial 4.0 International License. the incidence is 44 to $55 \%^{2}$. It is estimated that $0.8 \%$ to $4.4 \%$ of children will develop inguinal hernia during the process of their growth ${ }^{3}$. Inguinal hernia repair is one of the most frequent operations in pediatric surgery and is also essential for the surgical training of resident doctors as a basic surgical skills ${ }^{4,5}$. In choosing the appropriate method of inguinal hernia repair, the pediatric surgeon considers the complications and outcome of each method. The two most commonly used methods are the Ferguson technique and the Mitchell-Bank technique ${ }^{6,7}$. The choice of the operative technique depends upon the outcome and anticipated complications. While the former technique involves incision over the external ring and aponeurosis, the latter does not. The usual complications that follow are scrotal edema and hematoma, wound infection, recurrence and testicular atrophy ${ }^{8}$. The aim of this study was to evaluate the complications following repair of inguinal hernia in children.

\section{METHODOLOGY}

Ethical approval was obtained from the ethics and research committee of Enugu State University Teaching Hospital (ESUTH). This was a retrospective study done in children aged 15 years and below who developed 
complications following surgery for inguinal hernia repair (both emergency and elective) at the pediatric surgery unit of Enugu State University Teaching Hospital (ESUTH) Enugu, Nigeria, between January 2014 and December 2018. Children who developed complications following inguinal hernia repair both at the peripheral hospital and at ESUTH were recruited into the study. Patients with anesthetic complications and those older than 15 years were excluded. Information was extracted from the case notes, operation notes, operation register, and admission-discharge records. Relevant information was collected using clinical and operative records. Demographic details and temporal profile of repair along with outcome of treated complications were studied. The patients were followed up for 12 months. Statistical analysis was done using ( statistical package for social sciences (SPSS) version 21. Data were expressed as percentage, median, mean and range.

\section{RESULTS}

\section{PATIENTS' DEMOGRAPHY}

A total of 123 out of the 1243 children undergoing hernia repair developed complications accounting for a rate of $9.9 \%$. The ages of the patients ranged from 3 weeks to 11 years with a median of 1 year. Majority of the patients were infants. Age groups of the patients are depicted in Table 1. There were 92 (74.8\%) males and 31 (25.2\%) females. Sixty-five (52.8\%) inguinal hernia repairs were performed as emergencies and 58 (47.2\%) cases were performed as elective surgeries. The mean duration of hospital stay was 6 days with a range of 1 to 10 days.

Contents of the hernia sac are shown in Table 2. All the contents of the hernia were found to be viable at surgery. The nature of the emergency hernia is reflected in Table 3.

\section{Nature of the complication and the average postoperative period when it was noticed}

The complications encountered in the repair of the inguinal hernias are shown in Table 4. Complications of inguinal hernia repair and the average postoperative day they were noticed. Patients who had recurrent inguinal hernias were noticed to have an associated undescended testis $(n=123)$.

\section{Outcome}

All the scrotal edema and hematoma resolved spontaneously. Wound infections were cleared and the wounds healed. Patients with recurrent inguinal hernia had their hernias repaired and made full recovery.
Patients with testicular atrophy and sensory loss are still being followed up. There was no mortality.

\section{Table 1: Age groups of the patients}

\begin{tabular}{lc}
\hline Age group & Number of children (\%) \\
\hline Neonates (< 1 month) & $20(16.3)$ \\
\hline Infants (1-12 months) & $82(66.7)$ \\
\hline 12 months to 5 years & $21(17.0)$ \\
\hline
\end{tabular}

Table 2: Contents of the hernia sac

\begin{tabular}{lc}
\hline Contents of the hernia sac & Number of patients (\%) \\
Intestine & \\
Small intestine & $39(31.7)$ \\
Large intestine & $2(1.6)$ \\
\hline Omentum & $33(26.8)$ \\
\hline Tubo ovarian structure & None \\
Side of the hernia & \\
Right & $74(60.2)$ \\
Left & $49(39.8)$ \\
\hline
\end{tabular}

Table 3: Nature of the emergency inguinal hernia

\begin{tabular}{cc|}
\hline Nature of the emergency & Number of patients \\
\hline Incarceration & 31 \\
\hline Obstruction & 20 \\
\hline Strangulation & 14 \\
\hline
\end{tabular}

Table 4: Complications encountered in the repair of the inguinal hernia

\begin{tabular}{lcc}
\hline Complications & $\begin{array}{c}\text { Number of } \\
\text { patients (\%) }\end{array}$ & APPCN \\
\hline Scrotal edema & $32(26.0)$ & $6^{\text {th }}$ day \\
\hline Scrotal hematoma & $22(17.9)$ & $4^{\text {th }}$ day \\
\hline Wound infection & $21(17.1)$ & $7^{\text {th }}$ day \\
\hline Hernia recurrence & $19(15.4)$ & $4^{\text {th }}$ month \\
\hline Testicular atrophy & $19(15.4)$ & $6^{\text {th }}$ month \\
$\begin{array}{l}\text { Sensory disturbances in } \\
\text { the groin region }\end{array}$ & $10(8.2)$ & $10^{\text {th }}$ month \\
\hline
\end{tabular}

APPCN $=$ Average Postoperative period complication was noticed

Table 5: Treatment offered for complications

\begin{tabular}{ll}
\hline Complications & Treatment offered \\
\hline Scrotal edema & Scrotal support and observation \\
\hline Scrotal hematoma & Scrotal support and observation \\
\hline Wound infection & Antibiotics and wound dressing \\
\hline Hernia recurrence & Repeat hernia repair \\
\hline Testicular atrophy & Observation \\
\hline $\begin{array}{l}\text { Sensory impairment } \\
\text { in the groin region }\end{array}$ & Observation \\
\hline
\end{tabular}




\section{DISCUSSION}

The processus vaginalis which is an outpouching of the peritoneum descends with the testis retroperitoneally into the scrotum. The processus should obliterate naturally; failure of the processus vaginalis to obliterate results in inguinal hernia9. Once inguinal hernia develops, it must be repaired surgically ${ }^{10}$. Historically, repair of inguinal hernia has passed through many era of development: Ancient era, herniology era, anatomic era, era of repair under tension and era of tensionless repair ${ }^{11}$. The modern principles of hernia repair include: aseptic hernia operation, high ligation of the sac, narrowing of the internal ring and tensionless repair ${ }^{11}$.

In the present study, complications following repair of inguinal hernia in children accounted for $9.9 \%$ of the total inguinal hernia repairs during the study period. One study from Iran reported a complication rate of $2 \%$. Complications arising from inguinal hernia repair may depend on the expertise of the surgeon and state of the hernia (complicated/uncomplicated). For instance, a study from Japan reported a high complication rate of $11.5 \%$ when the inguinal hernia is repaired by resident doctors as compared to when the repair is performed by consultants ${ }^{5}$. A study from Ilorin, Nigeria reported a complication rate of $24.4 \%$ following repair of complicated inguinal hernia ${ }^{12}$. The age range of our patients is similar to the findings of Taqvi et $\mathrm{al}^{8}$. However, it is important to note that inguinal hernia can present at any age and complications may occur at any age of repair. The male predominance recorded in the present study is consistent with the reports of other researchers ${ }^{8}$, ${ }^{13}$. In the index study, complications from inguinal hernia repair were found more in emergency cases due to incarceration, obstruction or strangulation. Davies et al reported higher post-operative complications in emergency hernia surgery particularly when there is bowel resection ${ }^{14}$. The high risk of wound infection and poor delineation of tissue planes may explain the association between inguinal hernia repair and post-operative complications in emergency surgeries. Patients' and environmental factors may be responsible for the high infection rate recorded in the present study. Infants (less than 1 year of age) were the age group of our patients mostly affected. Bamigbola et al also reported a high percentage of complications in inguinal hernia repair in infants ${ }^{12}$. The exact reason for this is not clear but the high incidence of inguinal hernias in infants may explain it. Most inguinal hernias are diagnosed and treated in infants. The length of hospitalization of children who were treated for complications of inguinal hernia repair depends on the nature of the complication.
For example, patients with wound infection may require prolonged hospital stay due to repeated wound dressing while patients with scrotal edema can be observed on an outpatient basis. The degree of wound infection determines if wound infection is managed as in-patient or out-patient.

Scrotal edema is a common complication following inguinal hernia repair in children and was the most common complication observed in the current study. Scrotal edema is regarded as a complication because the degree of scrotal edema varies from one patient to another and is a source of anxiety to the caregivers. Other authors also reported scrotal edema as a frequent complication of inguinal hernia surgery ${ }^{8,15}$. The loose areolar tissues of the scrotum and the scrotal dissections performed during surgery may explain the scrotal edema. Inadequate hemostasis during surgery may lead to accumulation of blood in the scrotal sacs leading to scrotal hematoma. The high rate of scrotal hematoma (17.9\%) recorded in the present study may be explained by the fact that some of the hernia repair was performed by resident doctors with poor hemostatic skills. None of the patients had surgical exploration for control of bleeding. None of the hematoma was expanding and there was no pyocele. There was no drainage or hematoma evacuation. All the hematoma resolved spontaneously. Differentiation of scrotal edema from hematoma was clinical. No radiological confirmation was done. The repair of inguinal hernia is generally a clean procedure with low risk of infection. However, when wound infection occurs, inguinal hernia repair is associated with hernia recurrence ${ }^{16}$. This is evidenced by the fact that hernia recurrence was seen in patients who had wound infection in the immediate post-operative period. No spreading cellulitis was noticed and oral broad spectrum antibiotics were given empirically for one week. Occlusive dressing using honey was the preferred modality of wound care. Diagnosis of wound infection was clinical evidenced by purulent effluent from the wound. Inguinal hernia recurrence occurred more in incarcerated hernias who presented emergently and had emergency repair. Tissue edema, distorted anatomy of the inguinal area and difficult surgery in emergency cases may explain the hernia recurrence. Testicular atrophy is an uncommon but well recognized complication of inguinal hernia repair ${ }^{17}$. Testicular atrophy may have resulted from compromised testicular blood supply to the testis due to pressure from an irreducible hernia. The risk of testicular atrophy is more in children who are less than 2 years and those with undescended testis ${ }^{17}$.In the present study, two-thirds (12 out of 19) of the patients 
that had testicular atrophy were patients that presented with incarcerated hernia. Testicular atrophy was noticed on the average 6 months post-operatively. Surgery for repair of inguinal hernia has been described as a minor surgery that can cause major pain ${ }^{18}$. This is due to sensory disturbances and neuropathic pain that may occur following inguinal hernia repair ${ }^{18}$. Pain in neonate was assessed by behavioral responses such as facial actions (brow bulge, eye squeeze) during blood sample collections.

Treatment of complications resulting from inguinal hernia repair depends on the nature of complication. Children with scrotal edema and hematoma can be observed and followed up for spontaneous resolution. However, there are reports of massive penoscrotal hematoma that required drainage and drain insertion ${ }^{19}$. Hernia recurrence will require another hernia repair. Repair of recurrent inguinal hernia in children presents a challenge to the pediatric surgeon and may require a mesh ${ }^{20,21}$. However, we do not use mesh for repair of recurrent inguinal hernia in my centre. Although sensory disturbances in the inguinal region is a wellknown complication of inguinal hernia repair, it is far less common in children ${ }^{22}$. The sensory disturbances following inguinal hernia repair was picked up by stimulation of the inguinal region and scrotum using a piece of cotton. Absence of cremasteric reflex or no contraction of the anal verge signifies sensory impairment. Management of this sensory impairment is expectant.

\section{REFERENCES}

1 NazemM, Dastgerdi MM, Sirous Fard M. Outcomes of pediatric inguinal hernia repair with or without opening the external oblique muscle fascia. J Res Med Sci. 2015; 20(12): 1172-6. [DOI]

2. Aihole JS. The demographic profile and management of infantile inguinal hernia: a 3-year's review. Afr J Urol. 2020; 26, 28. [DOI]

3. Lloyd DA, Rintala RJ: Inguinal hernia, in O'Neill JA, Jr (ed): Pediatric Surgery, St. Louis: Mosby-Year Book, Inc, 1998; 5: 1071-86

4. Gupta DK, Rohatgi M. Inguinal hernia in children: an Indian experience. Pediatr Surg Int. 1993; 8: 466-8. [DOI]

5. Yoshimura S, Migita M, Matsufuji H. The clinical outcomes of pediatric inguinal hernia repairs operated by surgical residents. Asian J Surg. 2020; 43(7): 730-4. [DOI]

6. Kurlan $\mathrm{MZ}$, Wels $\mathrm{PB}$, Piedad OH.Inguinal herniorrhaphy by the Mitchell Banks technique. J Pediatr Surg. 1972; 7(4): 427-9. [DOI]
In the present study, management outcome of the complications arising from inguinal hernia repair was good. All the patients recovered with no mortality. Other series also did not record any mortality ${ }^{8,13}$.

\section{LIMITATIONS OF THE STUDY}

This study was limited by the small number of patients. A larger number would have availed better analysis. Children who had anesthetic complications were excluded. Different methods of inguinal hernia repair were not considered. Standardization of the procedure could not be achieved because some of the patients were referred from the peripheral hospital.

\section{RECOMMENDATIONS}

Preventive measures such as meticulous hemostasis during surgery are advised. Prompt referral and treatment of inguinal hernias as elective surgeries is advised: Emergency repair is fraught with complications.

\section{CONCLUSION}

Complications may arise from the inguinal hernia repair in children and these complications occurred more in infants who underwent emergency surgeries. Scrotal complications are quite common and most treatments are non-operative. Parental awareness and enlightenment of primary care physicians are needed for early referral.

7. Summers JE. Inguinal herniorrhaphy; methods of repair in use at the present time. Am J Surg. 1950; 80(5): 540-4. [DOI]

8. Taqvi SR, Akhtar J, Batool T, Tabassum R, Mirza F. Complications of inguinal hernia surgery in children. J Coll Physicians Surg Pak. 2006; 16(8): 532-5 [PubMed]

9. Brandt ML. Pediatric hernias. SurgClin North Am. 2008; 88(1): 27-43, vii-viii. [DOI]

10. Skinner MA, Grosfeld JL. Inguinal and umbilical hernia repair in infants and children. SurgClin North Am. 1993; 73(3): 439-49. [DOI]

11. Lau WY. History of treatment of groin hernia.World J Surg. 2002; 26(6): 748-59. [DOI]

12. Bamigbola KT, Nasir AA, Abdur-Rahman LO, Adeniran JO. Complicated childhood inguinal hernias in UITH, Ilorin.Afr J Paediatr Surg. 2012; 9: 227-30. [DOI]

13. Askarpour S, Peyvasteh M, Javaherizadeh $H$. Recurrence and complications of pediatric inguinal hernia repair over 5 years. Ann Pediatr Surg. 2013;9(2):58-60. [Google Scholar] 
14. Davies M, Davies C, Morris-Stiff G, Shute K. Emergency presentation of abdominal hernias: outcome and reasons for delay in treatment-a prospective study. Ann R Coll Surg Engl. 2007; 89(1): 47-50. [DOI]

15. Javaid S, Rasool N, Choudhry M. Incidence of PostOperative complications of Inguinal Hernia and Hydrocele Open Surgery in Children. PJMHS. 2018; 12(2): 440-2. [DOI]

16. Grosfeld JL, Minnick K, SheddF,West KW, Rescorla FJ, Vane DW. Inguinal hernia in children: factors affecting recurrence in 62 cases. J Pediatr Surg. 1991; 26(3): 283-7. [DOI]

17. Sonderman KA, Wolf LL, Armstong LB, Taylor B, Jiang $W$, Well BR et al. Testicular atrophy following inguinal hernia repair in children. 2018; 34: 553-60. [DOI]

18. Magnusson N, Hedberg M, Osterberg J, Sandblom G. Sensory disturbances and neuropathic pain after inguinal hernia surgery. Scandinavian Journal of Pain. 2010; 1(2): 108-11. [DOI]

19. Shah DK, . Massive penoscrotal haematoma following inguinal hernia repair: a case report. J Med Case Rep. 2008; 21: 357. [PubMed]

20. Abdelmohsen SM, Osman MA. Current Trend in the Management of Huge Recurrent Inguinal Hernia in Infants.A Case Series.Ommega J Pediatr. 2017; 1(1): 1-7.

21. Soto LJ, Saltzman DA.The use of prosthetic mesh for the pediatric hernia repair. Meshes: Benefits and Risks.2004; 306-318. [DOI]

22. Kristensen $A D$, Ahlburg $P$, Lauridsen $M C$, Jensen $T S$, Nikolajsen $L$. Chronic pain after inguinal hernia repair in children. BJA. 2012; 109(4): 603-8. [DOI] 